9-replication Ss and to increase over trials for 18-replication Ss, but neither tendency was statistically significant.

For one S, significantly more than half of his filler LPs ( 10 of $12, p=.039$ ) had mean ratings higher than the mean of his 15 constant-set LPs. One $S$ showed a statistically significant tendency for the mean of his ratings of filler items to become increasingly larger than the mean of his ratings of constant-set LPs over replications ( $F=2.05$ with 17 and $256 \mathrm{df}, \mathrm{p}<.05)$. The overall difference between the mean rating assigned filler items and the mean rating assigned constant-set items did not reach statistical significance for any individual $\mathrm{S}$.

\section{DISCUSSION}

Three aspects of the present study may represent limitations on the generalizability of these results. The task was an extremely long one, requiring roughly $6 \mathrm{~h}$ of judgments from each 18-replication $S$ and $3 \mathrm{~h}$ from each 9-replication $S$. Boredom may thus account for the Ss' favorable reactions to novelty. Second, most Ss knew a great deal about the LPs before they volunteered for the experiment, to which information little may have been added by examination of the album covers. Finally, the information presented about each LP was precisely the same every time $S$ encountered it-presumably a much different situation from that which pertains in successive encounters with a particular person.

On the other hand, the fact that the present analysis was thought of only after all data had been collected suggests that $E$ effects are unlikely to have influenced the Ss' tendencies with respect to the familiarity-novelty issue.

\section{REFERENCES}

BERLYNE, D. E. Conflict, arousal, and curiosity. New York: McGraw-Hill, 1960.

HARRIS, R. J. Stimulus sampling models of post-decision dissonance phenomena. (Doctoral dissertation, Stanford University, 1967.) Ann Arbor, Michigan: Order No. 68-11, 304.

HOMANS, G. C. The human group. New York: Harcourt, Brace, \& World, 1950.

MOSTELLER, F., \& TUKEY, J. W. Data analysis, including statistics. In G. Lindzey and E. Aronson (Eds.), Handbook of social psychology (2nd ed.), Vol. 2. Menlo Park, Calif.: AddisonWesley, 1968.

SAMUELSON, P. A. Economics: An introductory analysis. New York: McGraw-Hill, 1964. NOTES

1. The data on which this paper is based were collected in the course of fulfilling the requirements for the $\mathrm{PhD}$ at Stanford University. Reanalysis of these data for present purposes was accomplished while the author was serving as Research Associate at the Palo Alto Veterans Administration Hospital. Mr. Richard Gurley and Miss Itsuye Sakai performed most of the statistical analyses reported herein.

2. Now at the University of New Mexico.

3. A more detailed presentation of the methods of this study is available in Harris (1967).

4. Ten Ss were run in the nine-replication condition, but the data on one S's ratings and choices of filler LPS were aceidentally discarded.

\title{
Heart rate and skin conductance responding during three attention-direction tasks
}

\author{
ROSS BUCK, ROBERT E. MILLER, and \\ WILLIAM F. CAUL, Laboratory of Clinical \\ Science, School of Medicine, University of \\ Pittsburgh, Pittsburgh, Pa. 15213
}

Subjects were instructed to turn their attention toward: (1) feeling their internal bodily events (BODY task); (2) remembering events that happened to them on the preceding day (COGNITIVE task); and (3) looking at a series of slides (EXTERNAL task). They were assured that no verbal report would be required. Cardiac deceleration occurred during the BODY and EXTERNAL tasks. The BODY task was associated with a decrease on skin conductance measures.

Lacey found that cardiac deceleration accompanied tasks which demanded that Ss attend to environmental events, and that acceleration occurred during tasks which seemed to require a rejection of environmental stimuli (Lacey, 1959; Lacey, Kagan, Lacey, \& Moss, 1963). The interpretation of these results has been questioned recently in a series of papers by Campos \& Johnson (1966, 1967; Johnson \& Campos, 1967). These authors demonstrated that either preparation to verbalize or actual verbalization led to cardiac acceleration to both acceptance and rejection tasks. They pointed out that Lacey's tasks involving environmental rejection involved implicit verbalization, while the environmental acceptance tasks did not. They concluded that the verbalization requirement was responsible for the cardiac accelerations in the rejection tasks of Lacey et al and that this could be the actual cause for the differences in direction of cardiac change.

One purpose of this study is to determine whether differential heart rate responding can be demonstrated to tasks involving environmental acceptance and rejection when Ss have been instructed that no overt verbalization will be required.

Another focus of this study involves the place that tasks involving proprioceptive stimuli occupy on the continuum between environmental acceptance and rejection. According to Lacey's definition of environmental rejection tasks as involving "the internal manipulation of symbols and the retrieval of stored information [Lacey et al, 1964]," proprioceptive stimuli should be included among "environmental events" since they are external to such cognitive processes, and attention to such stimuli should be associated with cardiac deceleration. However, if the need to shut out distracting external stimuli is the basis for the cardiac acceleration, and since it is probable that external stimuli can interfere with the act of attending to proprioceptive stimuli, it may be that attention to such stimuli is associated with cardiac acceleration. To explore this problem, this experiment investigated the heart rate and skin conductance responses to a task involving attention to proprioceptive stimuli: the task of attending to internal bodily events.

\section{SUBJECTS}

Subjects (Ss) were 12 male undergraduates recruited and paid $\$ 2.50$ through the student employment service at the University of Pittsburgh. 
Table 1

Heart Rate and Skin Conductance Scores for the Three Tasks

\begin{tabular}{|c|c|c|c|c|}
\hline & & Preinstruction & $\begin{array}{c}\text { Task minus } \\
\text { Preinstruction } \\
\text { Difference }\end{array}$ & $t$ \\
\hline $\begin{array}{l}\text { Heart } \\
\text { Rate } \\
\text { (BPM) }\end{array}$ & $\begin{array}{l}\text { Body } \\
\text { Cognitive } \\
\text { External }\end{array}$ & $\begin{array}{l}79.67 \\
80.83 \\
81.42 \\
\end{array}$ & $\begin{array}{l}-2.28 \\
-1.25 \\
-4.50 \\
\end{array}$ & $\begin{array}{l}2.32^{*} \\
0.71 \\
3.62^{* * *}\end{array}$ \\
\hline $\begin{array}{l}\text { Skin } \\
\text { Conductance } \\
\text { (Log } \mu \text { mhos } \times 100)\end{array}$ & $\begin{array}{l}\text { Body } \\
\text { Cognitive } \\
\text { External }\end{array}$ & $\begin{array}{l}119.23 \\
117.13 \\
118.46 \\
\end{array}$ & $\begin{array}{l}-1.67 \\
+1.56 \\
+0.36 \\
\end{array}$ & $\begin{array}{l}3.57^{* * *} \\
0.76 \\
0.39 \\
\end{array}$ \\
\hline $\begin{array}{l}\text { Skin } \\
\text { Conductance } \\
\text { Responses } \\
\text { (No. per min) }\end{array}$ & $\begin{array}{l}\text { Body } \\
\text { Cognitive } \\
\text { External }\end{array}$ & $\begin{array}{l}3.00 \\
2.67 \\
2.33\end{array}$ & $\begin{array}{l}-1.64 \\
-0.65 \\
+0.19\end{array}$ & $\begin{array}{l}2.89^{* *} \\
1.07 \\
0.42\end{array}$ \\
\hline
\end{tabular}

\section{PHYSIOLOGICAL MEASURES}

Heart rate (HR) and skin conductance (SC) were monitored by a Grass Model 7 polygraph equipped with a Model 7P5A wide-band ac preamplifier for HR measurement and a Model 7P4A low-level dc preamplifier for SC measurement. Skin conductance measurement was accomplished by $1 / 4-$ in. diam zinc electrodes attached with zinc sulfate electrode paste in a unipolar arrangement (Lykken, 1959). PROCEDURE

The $S$ sat in an adjustable dental chair, facing a 6-ft-high wooden divider. A shutter in the divider concealed an $8 \times 8$ in. backlighted velum screen. An automatic slide projector and a loudspeaker were positioned behind the divider. Ss were told that the experiment was concerned with physiological responding during different states of mind. Tape-recorded instructions for three tasks were presented over the loudspeaker. $S$ was given $3 \mathrm{~min}$ to concentrate on a task and was then told to stop concentrating and to just let his mind wander. After a 2-min rest period, the next set of instructions was presented. The three tasks were presented in all possible orders over the experiment. After the third task ended, $S$ rated how difficult he found each task to be.

One set of instructions directed $\mathrm{S}$ to turn his attention toward internal bodily events (BODY task). S was told to concentrate completely on events that he could feel going on in the interior of his body. A second set of instructions directed him to turn all of his attention to remembering and mentally going over events that had happened to him the day before (COGNITIVE task). A third set of instructions told $S$ to concentrate on looking at a series of six slides that was presented on the screen in front of him (EXTERNAL task). The slides were chosen in a pilot study to have interesting, but not arousing, content. ${ }^{2}$ Each slide was visible for $30 \mathrm{sec}$. On all tasks, $\mathrm{S}$ was asked to concentrate his attention completely on the tasks, and to avoid any thing that would divert his attention. He was assured that he would not have to report about any aspect of the task at any later time.

Physiological data were scored for the 1 min preceding the onset of each set of instructions (baseline period) and for the 3-min period following the end of the instructions and preceding the instructions to stop (task period). Heart rate scores were obtained by counting the number of beats per minute occurring during the measurement periods. Mean SC-level scores were computed by averaging the $\log$ of the reciprocals of skin resistance readings taken $30 \mathrm{sec}$ apart during the periods. Mean SC-response scores were obtained by counting the total numbers of deflections in skin resistance larger than $500 \mathrm{ohms}$ occurring during the periods and converting to the number per minute.

\section{RESULTS AND DISCUSSION}

HR data, presented in Table 1 , revealed that both the EXTERNAL and BODY tasks led to cardiac deceleration while the COGNITIVE task was associated with no HR change. The bradycardias to the EXTERNAL task were of greater magnitude $(p<.01)$ than those to the BODY task. The HR response to the COGNITIVE and EXTERNAL tasks was significantly different $(p<.05)$. Analysis of SC data indicated that the only significant effects of the differential instructions were decreases in both level and number of responses during the BODY task. The questionnaire data revealed that the BODY task was rated as significantly more difficult than either the COGNITIVE task $(p<.01)$ or the EXTERNAL task $(p<.001)$. The COGNITIVE and EXTERNAL tasks did not differ in rated difficulty.

These results indicate that the EXTER. NAL task was associated with HR deceleration but that no significant acceleration occurred to the COGNITIVE task. These findings are consistent with those found by Campos and Johnson in their "no verbalization" conditions. The finding of no HR change to the COGNITIVE task when verbalization is minimized is consistent with their conclusion that the HR accelerations to rejection tasks in previous studies were due to a verbalization requirement. The differential HR and lack of differential SC responding to the two tasks suggests, however, that the results of previous studies are not entirely due to different verbalization requirements. As long as verbalization is minimized, the HR deceleration to acceptance tasks seems to appear reliably.

The finding that the BODY task led to HR deceleration suggests that it should be considered to be an acceptance task. However, this interpretation is complicated by the significant $\mathrm{SC}$ decrease that accompanied this task, and by the fact that the BODY task was rated as more difficult than the other tasks. It appears that the BODY task, as manipulated in this experiment, differs from the other tasks on important dimensions other than the acceptance-rejection continuum. For this reason, the HR response to the BODY task cannot be interpreted unambiguously in terms of environmental rejection and acceptance.

\section{REFERENCES}

CAMPOS, J. J., \& JOHNSON, H. J. The effects of verbalization instructions and visual attention on heart rate and skin conductance. Psychophysiology, 1966, 2, 305-310.

CAMPOS, J. J., \& JOHNSON, H. J. The effect of affect and verbalization instructions of directional fractionation of autonomic response. Psychophysiology, 1967, 3, 245-290.

JOHNSON, H. J., \& CAMPOS, J. J. The effect of cognitive tasks and verbalization instructions on heart rate and skin conductance. Psychophysiology, 1967, 4, 143-150.

LACEY, J. I. Psychophysiological approaches to the evaluation of psychotherapeutic process and outcome. In E. A. Rubenstein and M. B. Parloff (Eds.), Research in psychotherapy. Washington, D.C.: American Psychological Association, 1959

LACEY, J. I., KAGAN, J., LACEY, B. C., \& MOSS, H. A. The visceral level: Situational determinants and behavioral correlates of autonomic response. In P. Knapp (Ed.), Expression of the emotions in man. New York: International Unive rsities, 1963.

LYKKEN, D. T. Properties of electrodes used in electrodermal measurement. Journal of Comparative \& Physiological Psychology, 1959, 52, 629-634.

\section{NOTES}

1. This investigation was supported by Research Grant MHO-0487 from the National Institute of Mental Health of the National Institutes of Health, United States Public Health Service, and by the Commonwealth of Pennsy lvania.

2. The slides were varied in the ambiguity of their content and detail. Two were out of focus and were indistinct in both content and detail. Two had distinct detail, but the content was unclear, as in a multiple exposure. The remaining slides, including photographs of Tcheletchew's painting "Hide and Seek," and Card 11 from the TAT, contained distinct content and detail. Order of presentation was randomized independently for each S. Analysis of variance revealed that the physiological responses to the slides did not differ significantly. 